J. Clin. Chem. Clin. Biochem.

Vol. 27, 1989. pp. $631-637$

(C) 1989 Walter de Gruyter \& Co.

Berlin - New York

\title{
A Comparison of Reference Method Values for Calcium, Lithium and Magnesium with Method-Dependent Assigned Values
}

\author{
By W. R. Külpmann, R. Buchholz, C. Dyrssen and D. Ruschke \\ Technical Assistance: P. Maibaum \\ Institut für Klinische Chemie I, Medizinische Hochschule Hannover
}

(Received March 13/June 26, 1989)

Summary: Commercially available control sera were analysed by the reference methods for calcium, lithium and magnesium.

Calcium: The mean deviation of the target values for routine flame atomic absorption spectrometry from the reference method values was $-1.2 \%$, in the case of flame atomic emission spectrometry $-0.1 \%$. The assigned values of determinations by methylthymol blue and cresolphthalein showed a positive bias: +2.3 and $+2.2 \%$.

Lithium: Target values for routine flame atomic absorption spectrometry and flame atomic emission spectrometry were in generally good agreement with the reference method values (deviation $+1.7 \%$ and $+0.7 \%$ ), although the differences were dependent on concentration.

Magnesium: The assigned values for routine flame atomic absorption spectrometry yielded a mean bias of $-0.4 \%$ from the reference method value. The target values for absorption spectrometry after reaction with Magon and Calmagite, however, differed by $+8.2 \%$ and $+9.3 \%$ on average. These methods seem to be less suitable for the determination of magnesium in serum than FAAS and would have failed several times to meet the requirements of quality assessment.

\section{Introduction}

In 1982 it was proposed by Stamm (1) to substitute the method-dependent assigned value by the reference method value in accuracy control. This new concept is becoming more and more generally accepted. From 1989 onward it will be the basis of the new guidelines for quality assessment in the Federal Republic of Germany. Accuracy will then be evaluated more unequivocally and the comparability of results should improve; method-dependent assigned values for the numerous methods that are in use for the determination of the same quantity are no longer required. New methods can be introduced without delay, when reference method values for the corresponding quantity are available. In this study reference method values for calcium, lithium and magnesium are compared with method-dependent assigned values as declared by the manufacturers, in order to check which routine methods are possibly less accurate and might need improvement or must even be abandoned, when the new guidelines are used.

\section{Materials and Methods}

1. Calcium

1.1 Control sera that were analysed by the reference method:

1. Standard Reference Material 909 (SRM 909), National Institute of Standards and Technology, Washington, D.C., USA

2. Seronorm lot. No. 156, Nyegaard \& Co, Oslo, Norway

3. Biotrol 2, EPAM - Polyionique DMD Distributing AG, Schaffhausen, FRG

4. Biotrol 3, EPAM - Polyionique DMD Distributing AG, Schaffhausen, FRG

5. Cation-Cal Calibration Reference Nr. 118, American Dade, Miami/USA

6. Fluinorm N, lot No. 621607, Behring Institut, Marburg/ Lahn, FRG 
7. Kontrollogen L, lot No. 623121, Behring Institut, Marburg/ Lahn, FRG

8. Kontrollogen LP, lot No. 623207, Behring Institut, Marburg/Lahn, FRG

9. Moni-trol I, lot No. 178, Merz und Dade GmbH, München, FRG

10. Moni-trol II, lot No. 76, Merz und Dade GmbH, München, FRG

11. Serodos, lot No. 5530, Boehringer-Ingelheim, Ingelheim, FRG

12. Technicon SMAC Reference I, Product Nr. T 03-7120, Technicon Instruments Corporation, New York, USA

13. Validate A, lot No. 3528042 Gödecke AG, Berlin, FRG

14. Validate N, lot No. 3601042 Gödecke AG, Berlin, FRG.

1.2 Reference method values were established by flame atomic absorption spectrometry according to $1 . c$. $(2,3)$ which includes - as a prerequisite of all reference methods - a stringent protocol for calibration, number of measurements and criteria of acceptance as well as a time schedule, which must be followed strictly. Measurements were performed with an atomic absorption spectrometer AS-PE 403 (Perkin-Elmer, Norwalk, USA).

1.3 Routine methods. Method-dependent assigned values of control sera were available for the following routine methods:

1. Flame atomic absorption spectrometry

2. Flame atomic emission spectrometry

3. Absorption spectrometry after reaction with:

3.10 -Cresolphthalein

3.2 Glyoxal-bis-(2-hydroxyanil) (GBHA)

3.3 Methylthymol blue

\section{Lithium}

2.1 Control sera that were analysed by the reference method:

1. Standard Reference Material 909 (SRM 909), National Institute of Standards and Technology, Washington, D. C., USA

2. Control Serum N, lot No. E 3040, Hoffmann-La Roche AG, Grenzach-Wyhlen, FRG

3. Control Serum P, lot No. T 2440, Hoffmann-La Roche AG, Grenzach-Wyhlen, FRG

4. Fluinorm N, lot No. 621607, Behringwerke AG, Marburg/ Lahn, FRG

5. Kontrollogen L, lot No. 623119, Behringwerke AG, Marburg/Lahn, FRG

6. Kontrollogen L, lot No. 623120, Behringwerke AG, Marburg/Lahn, FRG

7. Kontrollogen LP, lot No. 623217, Behringwerke AG, Marburg/Lahn, FRG

8. M + D Lab-trol E, lot No. LT-105, AHS/Deutschland $\mathrm{GmbH}$, Merz + Dade, München, FRG

9. $M+D$ Moni-trol I, lot No. 178, AHS/Deutschland GmbH, Merz + Dade, München, FRG

10. $M+D$ Moni-trol II, lot No. 68, AHS/Deutschland GmbH Merz + Dade, München, FRG

11. Pathonorm $\mathrm{H}$, lot No. 18, Nyegaard \& Co, Oslo, Norway

12. Precilip, lot No. 1-375, Boehringer Mannheim GmbH, Mannheim, FRG

13. Precinorm S, lot No. 1-318, Boehringer Mannheim GmbH, Mannheim, FRG

14. Precipath $S$, lot No. 1-303, Boehringer Mannheim GmbH, Mannheim, FRG

15. Precipath U, lot No. 3-521, Boehringer Mannheim GmbH, Mannheim, FRG

16. Serodos, lot No. 5530, Boehringer Ingelheim GmbH, Garching, FRG

17. Seronorm, lot No. 150 , Nyegaard \& Co, Oslo, Norway
18. Seronorm, lot No. 156, Nyegaard \& Co, Oslo, Norway

19. Validate A, lot No. 2423091, Gödecke AG, Berlin, FRG

20. Validate N, lot No. 2604051, Gödecke AG, Berlin, FRG.

Standard Reference Material SRM 909 (National Institute of Standards and Technology, Washington, D. C., USA), definitive value $1.65 \mathrm{mmol} / \mathrm{l}$ was used for accuracy control of the reference method.

2.2 Reference method values were established by flame atomic absorption spectrometry according to 1.c. (4). Measurements were performed with an atomic absorption spectrometer ASPE 403 (Perkin-Elmer, Norwalk, USA).

2.3 Routine methods. Method-dependent assigned values of control sera were available for the following routine methods:

1. Flame atomic absorption spectrometry

2. Flame atomic emission spectrometry

\section{Magnesium}

3.1 Control sera that were analysed by the reference method:

1. Standard Reference Material 909 (SRM 909), National Institute of Standards and Technology, Washington, D. C., USA

2. Control Serum N, lot No. P 1039, Hoffmann-LaRoche AG, Grenzach-Wyhlen, FRG

3. Control Serum P, lot. No. P 2439, Hoffmann-La Roche AG, Grenzach-Wyhlen, FRG

4. Fluinorm N, lot No. 621608, Behring Institut, Marburg/ Lahn, FRG

5. Gilford QCS abnormal, lot No. 25501, Ciba Corning Di= agnostics Corp., Irvine/CA, USA

6. Gilford QCS abnormal, lot No. $25505 \mathrm{E}$, Ciba Corning Diagnostics Corp., Irvine/CA, USA

7. Gilford QCS normal, lot No. 20501, Ciba Corning Diagnostics Corp., Irvine/CA, USA

8. Kontrollogen L, lot No. 623125, Behring Institut, Marburg/ Lahn, FRG

9. Kontrollogen LP, lot No. 623210, Behring Institut, Märburg/Lahn, FRG

10. Moni-trol I, lot No. LTD .208, Merz u. Dade GmbH, München, FRG

11. Moni-trol II, lot No. LTD 108, Merz u. Dade GmbH, München, FRG

12. Pathonorm $\mathrm{H}$, lot No. 21, Nycomed-AS, Oslo, Norway

13. Precinorm U, lot No. 153146, Boehringer Männheim GmbH, Mannheim, FRG

14. Seronorm, lot No. 166, Nyegaard \& Co, Oslo, Norwāy

15. Validate A, lot No. 4X065, Gödecke AG, Berlin, FRG

16. Validate N, lot No. 0 B 924 , Gödecke AG, Berlin, FRG

17. Validate N, lot No. 4 X 023, Gödecke AG, Berlin, FRG.

Standard Reference Material SRM 909 (National Institute of Standards and Technology, Washington, D.C., USA), definitive value $1.21 \mathrm{mmol} / \mathrm{l}$, was used for accuracy control of the reference method.

3.2 Reference method values were established by flame atomic absorption spectrometry according to 1.c. (5). Measurements were performed with an atomic absorption spectrometer 3030 (Perkin-Elmer, Norwalk, USA).

3.3 Routine methods. Method-dependent assigned values of control sera were available for the following routine methods:

1. Flame atomic absorption spectrometry

2. Absorption spectrometry after reaction with:

2.1 Magon

2.2 Calmagite 


\section{Results}

\section{Calcium}

\section{Precision and accuracy of the reference method}

The precision of the reference method values was calculated from the 4 contributing results. The mean relative standard deviation was $0.18 \%$ (range: $0.06-$ $0.25 \%$ ) (tab. 1). Hence the relative standard error of the mean was $0.09 \%$. The accuracy was checked by analysis of sera with certified definitive values and commercially available calibration solutions:

$3.02 \mathrm{mmol} / 1$ Reference method value: $3.008 \mathrm{mmol} / \mathrm{l}$

Seronorm: Definitive value: $2.39 \mathrm{mmol} / 1$ Reference method value: $2.384 \mathrm{mmol} / \mathrm{l}$

$2.50 \mathrm{mmol} / 1$ Reference method value: $2.485 \mathrm{mmol} / 1$

Cation-Cal: Target value:

$2.95 \mathrm{mmol} / \mathrm{l}$ Reference method value: $2.947 \mathrm{mmol} / \mathrm{l}$

Biotrol 3: Target value: $\quad 3.25 \mathrm{mmol} / \mathrm{l}$ Reference method value: $3.240 \mathrm{mmol} / 1$

Comparison of the reference method values with the method-dependent assigned values

Ten commercially available control sera were anlysed by the reference method. The reference method values agreed well with the target values of routine flame atomic absorption spectrometry (FAAS) and flame atomic emission spectrometry (FAES) as declared by the manufacturers (tab. 1). The mean bias of FAAS was $-1.2 \%$ (range: -3.0 to $-0.2 \% ; n=10$ ). The negative deviation increased slightly with increasing concentration. The FAES values differed by $-0.1 \%$ (range: -1.9 to $+3.4 \% ; n=13$ ). ( $n$ encompasses the number of all target values that were given by the manufacturers for a method. $n$ can exceed the number of control sera that were used, because several target values are given e.g. for FAES for the same control serum. The actual deviation is calculated from the mean of the method-dependent assigned values of a control serum, when more than one value is given for a method, e.g. for different flame atomic emission spectrometers. The range encompasses all values, which are given for a method.) A dependency of the bias on the concentration was not obvious. As compared with the reference method values the target values stated for absorption spectrometry after reaction with methylthymol blue were higher: Mean bias $+2.3 \%$ (range: +0.2 to $+11.0 \% ; n=11$ ). The difference decreased with increasing concentration. Target values for absorption spectrometry after reaction with cresolphthalein were $2.2 \%$ higher than the reference method values (range: -5.0 to $+8.0 \%$; $\mathrm{n}=20$ ). A dependency of the bias on the concentration was not evident. In the case of glyoxal-bis-(2hydroxyanil) the mean deviation from the reference method value approached $0.0 \%$ (range: -4.2 to $+3.6 \% ; n=7)$.

\section{Lithium}

\section{Precision and accuracy of the reference method}

The precision of the reference method value was calculated from the 4 results contributing to the reference method values of 18 control sera that were analysed. The mean relative standard deviation was $0.54 \%$, its range 0.16 to $1.02 \%$ (tab. 2). The reference method value of SRM 909 deviated from the definitive value by $-0.45 \%$.

Comparison of the reference method values with the umethod-dependent assigned values

The lithium concentration of 18 control sera was determined by the reference method. The target values as declared by the manufacturers for routine flame atomic absorption spectrometry were $1.7 \%$ higher (range: -4.4 to $+6.3 \% ; \mathrm{n}=14$ ) than the reference method values (tab. 2). The positive bias was most pronounced at low concentrations; at high concentrations the values were even lower than the reference method values. The target values for routine flame atomic emission spectrometry were $0.7 \%$ higher (range -5.7 to $+8.8 \% ; \mathrm{n}=25$ ) than the reference method values. At low concentrations a positive bias was predominant, whereas at higher concentrations differences became lower or even negative.

\section{Magnesium \\ Precision and accuracy of the reference method}

Sixteen control sera were analysed by the reference method. The mean relative standard deviation (CV) of the 4 results contributing to the reference method values was $0.48 \%$ (range: 0.18 to $1.07 \%$ ) (tab. 3 ). The reference method value agreed well with the definitive value that is certified for SRM 909. The mean bias was $-1.38 \%(n=2)$, which is within the confidence limits of the definitive value.

Comparison of the reference method values with the method-dependent assigned values

Target values stated by the manufacturers for routine flame atomic absorption spectrometry $(n=16)$ differed on average by $-0.4 \%$ from the reference 


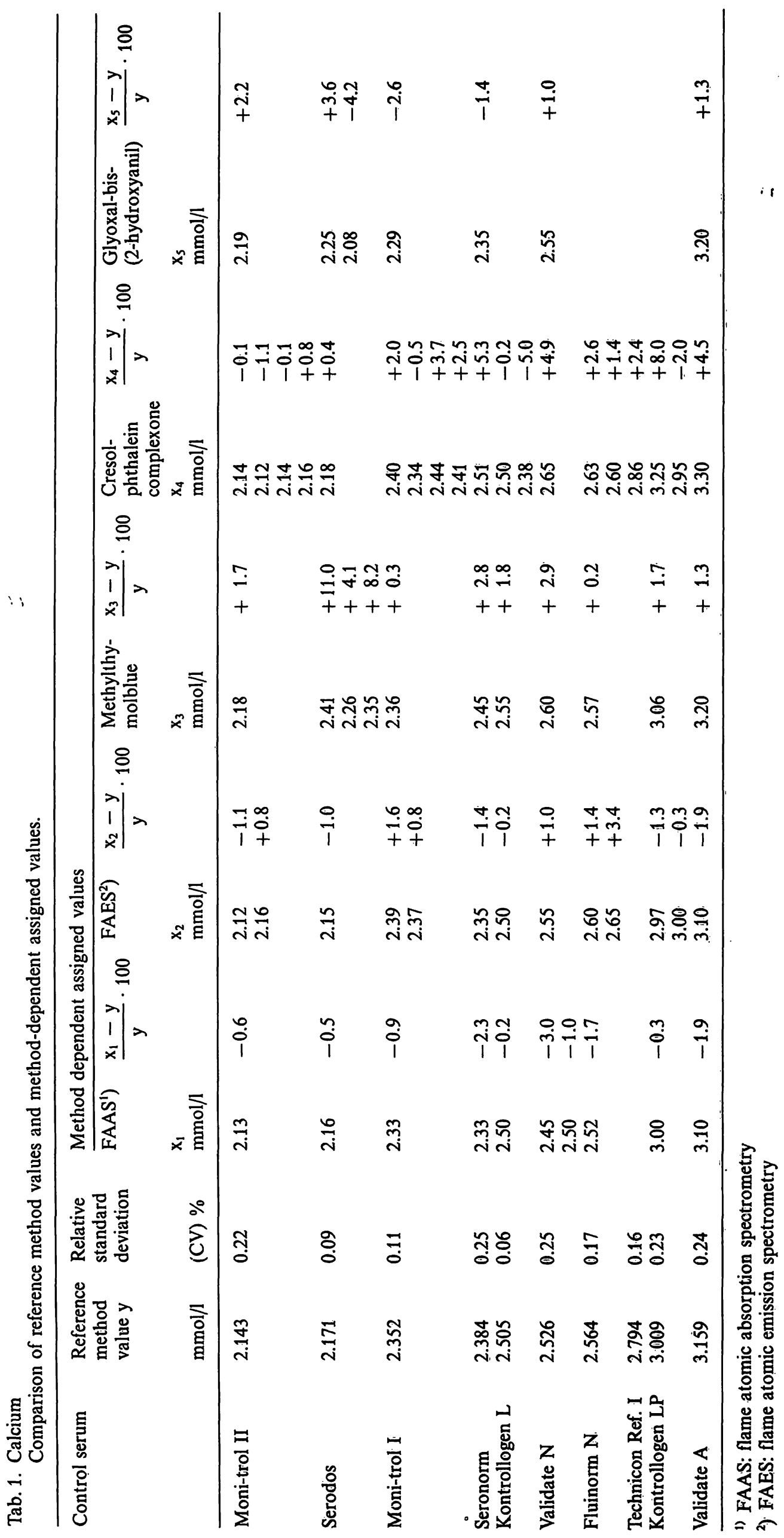


Tab. 2. Lithium.

Comparison of reference method values and method-dependent assigned values.

\begin{tabular}{|c|c|c|c|c|c|c|}
\hline \multirow[t]{2}{*}{ Control serum } & \multirow{2}{*}{$\begin{array}{l}\text { Reference } \\
\text { method } \\
\text { value y } \\
\text { mmol/1 }\end{array}$} & \multirow{2}{*}{$\begin{array}{l}\text { Relative } \\
\text { standard } \\
\text { deviation } \\
\text { (CV) } \%\end{array}$} & \multicolumn{4}{|c|}{ Method-dependent assigned values } \\
\hline & & & $\begin{array}{l}\left.\mathrm{FAAS}^{1}\right) \\
\mathrm{x}_{1} \\
\mathrm{mmol} / \mathrm{l}\end{array}$ & $\frac{x_{1}-y}{y} \cdot 100$ & $\begin{array}{l}\mathrm{FAES}^{2} \text { ) } \\
\mathrm{x}_{2} \\
\mathrm{mmol} / 1\end{array}$ & $\frac{x_{2}-y}{y} \cdot 100$ \\
\hline Lab-trol E & 0.507 & 0.68 & & & 0.54 & +6.5 \\
\hline Moni-trol I & 0.616 & 1.02 & 0.64 & +3.9 & 0.67 & +8.8 \\
\hline Seronorm $_{1}$ & 0.687 & 0.24 & 0.73 & +6.3 & 0.71 & +3.3 \\
\hline Serodos & 0.947 & 0.68 & & & 0.96 & +1.4 \\
\hline Validate $\mathrm{N}$ & 0.953 & 0.70 & 1.00 & +4.9 & 1.00 & +4.9 \\
\hline Seronorm $_{2}$ & 0.958 & 0.97 & 1.00 & +4.4 & 0.96 & +0.2 \\
\hline Pathonorm H & 0.993 & 0.49 & 1.03 & +3.7 & 0.98 & -1.3 \\
\hline \multirow[t]{2}{*}{ Kontrollogen L } & 1.039 & 0.83 & 1.05 & +1.1 & 0.98 & -5.7 \\
\hline & & & & & 1.05 & +1.1 \\
\hline Control Serum N & 1.126 & 0.36 & 114 & 110 & 1.10 & +5.9 \\
\hline \multirow{2}{*}{ Moni-trol II } & 1.456 & 0.19 & 1.07 & 11.2 & 1.14 & +1.2 \\
\hline & & & & & $\begin{array}{l}1.47 \\
1.40\end{array}$ & $\begin{array}{l}+1.0 \\
-3.8\end{array}$ \\
\hline \multirow[t]{3}{*}{ Fluinorm $\mathrm{N}$} & 1.515 & 0.22 & 1.55 & +2.3 & 1.55 & +2.3 \\
\hline & & & & & 1.45 & -4.3 \\
\hline & & & & & 1.62 & +6.9 \\
\hline \multirow[t]{3}{*}{ Kontrollogen LP } & 1.559 & 0.63 & 1.59 & +2.0 & 1.51 & -3.1 \\
\hline & & & & & 1.54 & -1.2 \\
\hline & & & & & 1.59 & +2.0 \\
\hline Validate $\mathrm{A}$ & 1.677 & 0.53 & & & 1.67 & -0.4 \\
\hline Control Serum P & 1.753 & 0.22 & 1.82 & +3.8 & 1.73 & -1.3 \\
\hline Precinorm S & 1.764 & 0.81 & 1.70 & -3.6 & 1.70 & -3.6 \\
\hline Precilip & 1.868 & 0.16 & 1.84 & -1.5 & 1.84 & -1.5 \\
\hline Precipath S & 2.030 & 0.75 & 1.94 & -4.4 & 1.94 & -4.4 \\
\hline Precipath U & 2.395 & 0.19 & 2.37 & -1.0 & 2.37 & -1.0 \\
\hline
\end{tabular}

1) FAAS: flame atomic absorption spectrometry

2) FAES: flame atomic emission spectrometry

Seronorm 1 lot No. 150

Seronorm $_{2}$ lot No. 156

method value. The bias seemed to be concentration dependent: In the concentration range 0.5 to 1.0 $\mathrm{mmol} / \mathrm{l}$ (range I) the mean deviation was $+1.0 \%$, in the concentration range $>1.0$ to $1.5 \mathrm{mmol} / \mathrm{l}$ (range II) $-1.4 \%$, and in the concentration range $>1.5$ (range III) $-1.7 \%$. The target values given for magnesium determinations by absorption spectrometry after reaction with Magon reagent differed by $+8.2 \%$ $(\mathrm{n}=19)$. At low concentrations (range I) the positive bias was most obvious $(+11.7 \%)$ and decreased with increasing concentrations: range II: $+7.5 \%$; range III: $+3.8 \%$. Six control sera with stated target values for absorption spectrometry after reaction with calmagite were analysed by the reference method. The mean deviation of the method-dependent assigned values from the reference method values was $+9.3 \%$. Depending on the manufacturer of the reagent, however, the target values differed to a small or to a great extent: For the same control serum the deviations were: $-6.8,-1.4,+4.1,+9.6$ and $20.5 \%$. The positive bias was most pronounced at low concentrations (range I): +13.8 and decreased at high concentrations: range II $+6.1 \%$, range III $4.1 \%$.

\section{Discussion}

The method-dependent assigned value is influenced by many factors: The reagents used for measurement, the calibration procedure, the adaption to a mechanized system often connected with some modification of the method, the statistical design of data collection and computation. Observed differences between a target value for a routine method and a reference method value must therefore be interpreted carefully. Changes in calibration procedure or reagents can improve a method as well as causing it to deteriorate. All statements that are derived from the figures presented hold true only in general. In the hands of a skilled expert a usually less reliable method can perform quite well. The tables present examples in which different target values are given for the same method for one control serum, some fitting well, some showing considerable disagreement.

Calcium: A satisfactory agreement between methoddependent assigned values and reference method values was observed in the case of FAAS and FAES. In FAAS one might suspect a slight deviation from lin- 
Tab. 3. Magnesium.

Comparison of reference method values and method-dependent assigned values.

\begin{tabular}{|c|c|c|c|c|c|c|c|c|}
\hline \multirow[t]{2}{*}{ Control serum } & \multirow{2}{*}{$\begin{array}{l}\text { Reference } \\
\text { method } \\
\text { value y } \\
\text { mmol/1 }\end{array}$} & \multirow{2}{*}{$\begin{array}{l}\text { Rclative } \\
\text { standard } \\
\text { deviation } \\
\text { (CV) \% }\end{array}$} & \multicolumn{6}{|c|}{ Method-dependent assigned values } \\
\hline & & & $\begin{array}{l}\left.\text { FAAS }^{1}\right) \\
\mathrm{x}_{1} \\
\mathrm{mmol} / \mathrm{l}\end{array}$ & $\frac{x_{1}-y}{y} \cdot 100$ & $\begin{array}{l}\text { Magon } \\
\mathrm{x}_{2} \\
\mathrm{mmol} / 1\end{array}$ & $\frac{x_{2}-y}{y} \cdot 100$ & $\begin{array}{l}\text { Calmagite } \\
\mathbf{x}_{3} \\
\mathrm{mmol} / \mathrm{l}\end{array}$ & $\frac{x_{3}-y}{y} \cdot 100$ \\
\hline Validate $\mathrm{A}$ & 0.748 & 0.66 & 0.75 & +0.3 & 0.87 & +16.3 & 0.88 & +17.6 \\
\hline Seronorm & 0.758 & 0.77 & 0.77 & +1.6 & 0.86 & +13.5 & & \\
\hline Control Serum N & 0.790 & 0.93 & 0.80 & +1.3 & 0.92 & +16.5 & & \\
\hline Gilford QCS normal & 0.878 & 0.25 & 0.90 & +2.5 & $\begin{array}{l}0.90 \\
1.10\end{array}$ & $\begin{array}{l}+2.5 \\
+25.3\end{array}$ & $\begin{array}{l}0.90 \\
1.00\end{array}$ & $\begin{array}{l}+2.5 \\
+13.9\end{array}$ \\
\hline Moni-trol I & 0.931 & 0.20 & 0.93 & -0.1 & 0.96 & +3.1 & & \\
\hline Validate $N_{1}$ & 0.960 & 0.94 & 0.98 & +2.1 & 1.05 & +9.4 & 1.11 & +15.6 \\
\hline Kontrollogen L & 0.986 & 0.26 & 0.98 & -0.6 & 1.08 & +9.5 & & \\
\hline Precinorm U & 1.006 & 0.71 & 0.99 & -1.6 & 1.01 & +0.4 & & \\
\hline Validate $\mathrm{N}_{2}$ & 1.037 & 0.48 & 1.05 & +1.3 & 1.12 & +8.0 & 1.10 & +6.1 \\
\hline Fluinorm N & 1.309 & 0.22 & 1.27 & -3.0 & 1.28 & -2.2 & & \\
\hline Pathonorm H & 1.391 & 0.18 & 1.36 & -2.2 & 1.72 & +23.7 & & \\
\hline Control Serum P & 1.557 & 1.07 & 1.52 & -2.4 & 1.65 & +6.0 & & \\
\hline Kontrollogen LP & 1.604 & 0.25 & 1.55 & -3.4 & 1.63 & +1.6 & & \\
\hline Gilford QCS abnormal $_{3}$ & 1.825 & 0.21 & 1.80 & -1.4 & $\begin{array}{l}1.90 \\
2.10\end{array}$ & $\begin{array}{l}+4.1 \\
+15.1\end{array}$ & $\begin{array}{l}1.70 \\
1.80 \\
1.90 \\
2.00 \\
2.20\end{array}$ & $\begin{array}{l}-6.8 \\
-1.4 \\
+4.1 \\
+9.6 \\
+20.5\end{array}$ \\
\hline Gilford QCS abnormal $_{4}$ & 1.942 & 0.20 & 1.90 & -2.2 & $\begin{array}{l}2.00 \\
2.10\end{array}$ & $\begin{array}{l}+3.0 \\
+8.1\end{array}$ & $\begin{array}{l}1.90 \\
2.10\end{array}$ & $\begin{array}{l}-2.2 \\
+8 .\end{array}$ \\
\hline Moni-trol II & 2.037 & 0.28 & 2.06 & +1.1 & 1.96 & $\begin{array}{l}T \\
-3.8\end{array}$ & & \\
\hline
\end{tabular}

1) FAAS: flame atomic absorption spectrometry

Validate $\mathrm{N}_{1}$ lot No. 4 X023

Validate $\mathrm{N}_{2}$ lot No. OB 924

Gilford QCS abnormal ${ }_{3}$ lot No. $25505 \mathrm{E}$

Gilford QCS abnormal 4 lot No. 25501

earity perhaps due to one point calibration. The procedures using absorption spectrometry distinctly yield a positive bias. In one case the deviation exceeded even the limits of the new guidelines (reference method value $\pm 10 \%$ reference method value) (6). With respect to additional poor precision, the requirements of quality assessment may not be met. Furthermore a method-dependent reference interval has to be established.

Lithium: According to the new guidelines (6) results by routine methods must not exceed: reference method value $\pm 12 \%$ reference method value. The target values given for FAAS and FAES were always within these limits, even though deviations increased at low and high concentrations.

Magnesium: The deviations of target values for routine FAAS from reference method values were adequately small, but dependent on concentration. Both methods using absorption spectrometry yielded a distinct positive bias. In 6 out of 20 (Magon) and 4 out of 12 the method-dependent assigned values exceeded the limits of the guidelines (reference method value $\pm 12 \%$ reference method value) (6). Although these discrepancies may be due partly to the matrix of the control sera, which is different from the matrix of native human sera (this can be presumed from an often acceptable agreement of results obtained by the methods when patients' sera are used and the difference between method-dependent assigned values of control sera), this result is unsatisfactory and clearly demonstrates that these methods are less robust than FAAS and more easily susceptible to interfering compounds. The magnitude of deviation seems to be dependent on the reagents that are used: For one control serum, 5 different target values for calmagite were given. They differed from the reference method value by $-6.8,-1.4,+4.1,+9.6$ and $+20.5 \%$.

The figures presented clearly underline that it is not advisable to use reference method values for calibration of routine methods. In addition to other effects, the matrix of the control serum often contains varying amounts of interfering factors, which lead to erroneous results with less specific methods.

\section{Acknowledgement}

The work was supported by Deutsche Gesellschaft für Klinische Chemie. 


\section{References}

1. Stamm, D. (1982) A New Concept for Quality Control of Clinical Laboratory Investigations in the Light of Clinical Requirements and Based on Reference Method Values. J. Clin. Chem. Clin. Biochem. 20, 817-824.

2. Brown, S. S., Healy, M. J. R. \& Kearns, M. (1981) Report on the Inter-Laboratory Trial of the Reference Method for the Determination of Total Calcium in Serum, Part I. J. Clin. Chem. Clin. Biochem. 19, 395-412.

3. Brown, S. S., Healy, M. J. R. \& Kearns, M. (1981) Report on the Inter-Laboratory Trial of the Reference Method for the Determination of Total Calcium in Serum, Part II. J. Clin. Chem. Clin. Biochem. 19, 413-426.
4. Velapoldi, R. A., Paule, R. C., Schaffer, R., Mandel, J., Machlan, L. A., Garner, E. L. \& Rains, T. C. (1980) Standard Reference Materials: A Reference Method for the Determination of Lithium in Serum. NBS Spec. Public. 260-69.

5. Külpmann, W. R., Ruschke, D., Büttner, J. \& Paschen, K. (1989) A Candidate Reference Method for the Determination of Magnesium in Serum. J. Clin. Chem. Clin. Biochem. 27, 33-39.

6. Anonymous (1988) Qualitätssicherung der quantitativen Bestimmungen im Laboratorium. Neue Richtlinien der Bundesärztekammer, Dt. Ärztebl. 85, B 517-B 532.

Prof. Dr. W. R. Külpmann Institut für Klinische Chemie I Medizinische Hochschule Hannover Konstanty-Gutschow-Straße 8 D-3000 Hannover 61 


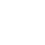

